\title{
Hayat Bilgisi Dersinde Kullanılan Dijital Platformların Çoklu Ortam Tasarım İlkelerine Göre Değerlendirilmesi
}

\section{Evaluation of Digital Platforms Used in Life Studies Lesson According to Multimedia Design Principles}

\author{
Mehmet Arif Özerbaş, Beyza Nur Safi, Şevval Türkoğlu
}

\section{Beyza Nur Safi}

Gazi Üniversitesi, Eğitim

Bilimleri Enstitüsü, Yüksek

Lisans Öğrencisi,

bbeyza718@gmail.com

\section{Şevval Türkoğlu}

Gazi Üniversitesi, Eğitim

Bilimleri Enstitüsü, Yüksek

Lisans Öğrencisi,

sevval.turkoglu.9@gmail.com

\begin{tabular}{l}
\hline Yazar Bilgileri \\
\hline Mehmet Arif Özerbaş \\
Prof. Dr., Manas Üniversitesi, \\
marif.ozerbash@manas.edu.kg
\end{tabular}

\section{ÖZ}

Bu araştırmanın amacı, dijital platformda bulunan üçüncü sınıf hayat bilgisi dersindeki videoların Mayer'in Çoklu Ortam Tasarım İlkeleri'ne göre değerlendirilerek tasarım ve geliştirme aşamasında ölçütlere ne düzeyde dikkat edildiğinin ortaya konulmasıdır. Araştırmada doküman incelemesi yöntemi kullanılmıştır. Araştırmanın örneklemini, dijital platformdaki ilkokul 3. sınıf hayat bilgisi dersinde yer alan 41 video oluşturmaktadır. Araştırmada Ozan (2013) tarafından hazırlanan çoklu ortam uygulamalarına ilişkin değerlendirme tablosundan faydalanılmıştır. Verilerin analizinde tekrarlı ölçümler için iki faktörlü ANOVA Testi kullanılmıştır. Araştırmadan elde edilen bulgulara göre videolarda konuyla bağlantısı olmayan ayrıntılara yer verilmemiştir. Ayrıca konu küçük parçalara bölünerek görseller ve sözel anlatım aynı anda verilmiştir. Bu bağlamda Mayer'in Çoklu Ortam İlkeleri'ne göre en yüksek puanları 'tutarlılık' ve 'zamansal bitişiklik' ilkesi almıştır. Videolarda, öğrenene anlatımı istediği zaman yazılı olarak görme imkânının sunulmaması Mayer'in çoklu ortam tasarım ilkelerinden 'gereksizlik' ilkesine uymamaktadır. Bunun sonucunda videolar gereksizlik ilkesi bağlamında en düşük puanla değerlendirilmiştir. Araştırmada uzmanlar tarafından Mayer'in Çoklu Ortam Tasarım İlkesi'ne göre değerlendirilen her video için verilen değerlendirme puanlarına bakıldığında bir ve ikinci uzman hariç farklı değerlendirme sonuçlarına ulaşmıştır. Araştırma sonucuna göre dijital platformlardaki içerikler mutlaka alanda uzman kişiler tarafından değerlendirilmeli ve eksik yönleri belirtilmelidir. Ayrıca yazılımları oluşturan kişiler alandaki araştırmaları ve gerekli değerlendirme ilkelerini göz önünde bulundurarak içerik üretmelidirler.

\begin{tabular}{ll} 
Makale Bilgileri & ABSTRACT \\
\hline $\begin{array}{l}\text { Anahtar Kelimeler } \\
\text { Hayat Bilgisi Dersi }\end{array}$ & $\begin{array}{l}\text { The purpose of this research is to evaluate the videos in the third grade Life Science course on } \\
\text { Çoklu Ortam }\end{array}$ \\
Tasarım Ilkeleri & $\begin{array}{l}\text { of attention to the criteria during the design and development phase. Document analysis } \\
\text { method was used in the study. The sample of the study consists of } 41 \text { videos in the primary } \\
\text { Dijital Platform }\end{array}$ \\
& $\begin{array}{l}\text { on multimedia applications prepared by Ozan (2013) was used. A two-factor ANOVA test was } \\
\text { used for repeated measures in the analysis of the data. According to the findings, details that }\end{array}$ \\
Keywords & $\begin{array}{l}\text { are not related to the subject were not included in the videos. In addition, the subject was } \\
\text { divided into small parts and visuals and verbal expression were given at the same time. In this }\end{array}$ \\
Life Studies Lesson & context, the highest scores according to Mayer's multimedia principles are 'consistency' and \\
Multimedia & 'temporal contiguity' principles. The fact that the learner is not provided with the opportunity \\
to see the narration in writing whenever he/she wants in the videos does not comply with the \\
Digital Platform
\end{tabular}

Önerilen Atıf Özerbaş, M. A., Safi, B. N. \& Türkoğlu, Ş. (2021). Hayat bilgisi dersinde kullanılan dijital platformların çoklu ortam tasarım ilkelerine göre değerlendirilmesi. TEBD, 19(1), 421-437. https://doi.org/10.37217/tebd.872751 


\section{Giriş}

Dünya üzerinde yaşanan küreselleşme ve bilgi teknolojilerindeki gelişmelere paralel olarak eğitim sistemlerinin de yeniden yapılandırılarak bu gelişmelerle uyumlu hâle getirilmesi zorunluluk hâline gelmiştir. Değişen koşullar ve teknolojik gelişmeler ile birlikte insanların bilgiye erişim ve bilgi paylaşım alanları da hızla değişmeye başlamıştır. İnternetin hayatımıza girmesi, bilgi teknolojilerinin yaygınlaşması ve bilgiye erişimin hızlanmasıyla birlikte günümüzde eğitim; hemen herkesin, her an bilgiye ulaşabileceği bir konuma ulaşmıştır. Aile eğitiminden sonra okul ortamında başlayan ilkokul düzeyindeki eğitim, bireylerin kişisel gelişimleri açısından önemli bir yere sahiptir. Geleceğin tasarımı olarak değerlendirilmesi gereken ilkokul eğitiminin, teknolojik gelişmelere uygun olarak düzenlenmesi toplumsal bir gerekliliktir. Gelişen teknoloji ile birlikte amaçlanan analitik düşünme, iş birliği gibi becerilerle öğrencilerin öğrenmede aktif yer almaları sağlanmak istenmektedir. Teknolojiyi eğitime entegre etmeye çalışan her proje için amaçlardan biri öğrenci ve öğretmenlerin etkin bilişim teknolojilerini kullanmalarını sağlamaktır. Eğitime entegre edilen teknolojide çeşitliliğin yanı sıra teknolojiyi etkili kullanabilmek için gerekli ve yeterli içeriğin de önemi artık fark edilmektedir.

Temel eğitimin başladığı ilkokullarda dahi geleneksel kara tahta ve tebeşir kullanımı yerini dijital eğitim araçlarına bırakmıştır. Teknoloji ile zenginleştirilmiş öğrenme ortamları, basit bilgisayar laboratuvarlarından donanımlı bilgisayarların, projektörlerin, internet bağlantısının ve haberleşme teknolojilerinin bulunduğu ortamlara dönüşmüştür (Ott, 2000). Bununla birlikte eğitimde ders niteliğine sahip içeriklerin ve bu alanda hizmet veren uygulama ve programların sayısının da artmasına neden olmuştur. Yeni nesil teknoloji altyapısına sahip bu eğitim modeli, geleneksel eğitim modelleriyle karşılaştırıldığında, eğitimde yalnızca teknolojik gelişmelerin kullanılması ile sınırlı kalmayıp destekleyici yöntem ve yeni stratejik hedeflerin de belirlenmesi gerektiğini de göstermektedir (Baturay ve Türel, 2013). Vizyon 2023'ün önemli amaçlarından biri, öğretim süreçlerinde dijital içerik ve beceri dönüşümleri oluşturmaktır. Bu hedef doğrultusunda dijital eğitimöğretim içeriği geliştirme ekosistemi, ulusal dijital içerik arşivi, yeni nesil ölçme araçları ve dijital öğrenme materyalleri geliştiren lider öğretmenler desteklenmektedir.

Öğretim artık sadece öğretmenin aktif olduğu değil, öğrencilerin de aktifleşmesi gereken bir öğretim ortamını gerekli hâle getirdi. Öğretmen artık bilgiyi öğreten değil, bilgiye ulaşmak ve dönüştürmek için yol gösteren, öğretim ortamını içinde bulunduğumuz çağın becerilerine (yaratıcılık, eleştirel düşünme, medya okuryazarlığı vb.) göre şekillendiren kimse hâline gelmiştir. Millî Eğitim Bakanlığının (MEB) Talim Terbiye Kurulunda yayınladığı 2018 Öğretim Programı'nda yer alan Türkiye Yeterlilikler Çerçevesinde (TYÇ) belirlenmiş sekiz anahtar yetkinliklerinden biri olan “dijital yetkinlik" kavramına programda şu şekilde yer verilmiştir; iş, günlük hayat ve iletişim için bilgi iletişim teknolojilerinin güvenli ve eleştirel şekilde kullanılmasını kapsar. Söz konusu yetkinlik, 
bilgiye erişim ve bilginin değerlendirilmesi, saklanması, üretimi, sunulması ve alışverişi için bilgisayarların kullanılması ayrıca internet aracılığıyla ortak ağlara katılım sağlanması ve iletişim kurulması gibi temel beceriler yoluyla desteklenmektedir (MEB, 2018). Bu yetkinliğin öğrenciye kazandırılması için öğretim ortamının teknolojiyle bütünleştirilmesi gerekmektedir.

Öğrenme ortamlarının, öğrenmeye hazır olanlar ile öğrenmeye yönelik verilerin doğru, güvenilir ve etkin bir biçimde buluşmasına olanak sağlayacak yapıda olması gerekmektedir. Etkin bir öğrenmenin gerçekleşmesi için öğrenmeye yönelik verilerin öğrenciler tarafından duyu organlarıyla algılanabilir nitelikte görsel, işitsel, deneysel yapıda olması ve bunların uygun yöntem ve araçlar kullanılarak aktarılması gerekmektedir. Bu alanda yapılan araştırmalar, etkili ve kalıcı bir öğrenmenin, birden çok duyuyu hedef alan uyarıcılardan oluşan çoklu öğrenme ortamlarında mümkün olabileceğini göstermektedir. Etkili öğrenmenin sağlanması için gerekli öğrenme ortamlarının çerçevesini çizen Çoklu Ortam Öğrenme Kuramı, dayanağını oluşturan ilkeleri ve kuralları ile bu alanda önemli bir yol gösterici olarak değerlendirilmektedir (Akkoyunlu ve Yılmaz, 2005).

Çoklu ortam, öğrenme-öğretme sürecinde tekstleri, bilişim teknolojileri aracıllğıyla görüntü, diyagram, şekil, video, canlandırma, ses gibi formlarla bütünleştirerek öğrenenlerin etkinleşmesini sağlayan eğitsel tasarılardır (Özerbaş, 2007). Türk Dil Kurumuna göre çoklu ortam, bilgisayarda metin, grafik, ses ve animasyon ögelerini birleştirerek sunan ortam, multimedya olarak belirtilmektedir (Türk Dil Kurumu [TDK], 2017). Bu uygulama öğrencinin öğretim ortamında daha aktif hâle gelmesinin sağlar.

Müfredatta olan çoğu konu öğretmenler tarafından öğrencilere somutlaştırılmadan, Piaget'in gelişim dönemleri göz önüne alınmadan anlatılmaktadır. Hedef kitlemiz olan ilkokul öğrencileri somut işlemler dönemi (7-11) içerisindedir. Anlatılan konularda ses, şekil, görüntü, animasyon kullanılması öğrenmenin anlamlandırılmasına yardımcı olacaktır. Çoklu ortam tanımında da bahsedildiği gibi bu uygulama hem öğrenciyi öğretim ortamında daha aktif hâle getirecek yani öğretim ortamındaki kontrol öğrenciye bırakılacaktır. Hem de öğretmenlerin konuları somut bir şekilde öğrencilere aktarmalarını sağlayacaktır. Yapılan araştırmalarda çoklu ortam tasarımları; Piaget'ye göre somut işlemler döneminde yer alan ilkokul öğrencilerine soyut içerikli matematik konularını somutlaştırarak anlamlı öğrenme gerçekleştirmelerine katkı sağlamaktadır (Olkun ve Toluk-Uçar, 2009).

Bu bağlamda, Morpa Kampüs, dijital platform, EBA (Eğitim Bilişim Ağı) vb. çoklu ortam uygulamaları kullanılmaktadır. Dijital platform etkileşimli ve canlandırmalı, konu anlatımlarını pekiştiren çalışma kağıtları, soru çözümü videoları, konu testleri, öğrenme alanlarına uygun eğitsel oyunlar ve elektronik kitaplar içinde bulunduran eğitim içeriklerindendir. Bu eğitim içerikleri, MEB 
kazanımları ve yapılandırmacı öğretim modeli göz önünde bulundurularak hazırlanmıştır. Bu platformlardan faydalanacak olan öğretmen ve öğrenci potansiyelinin yüksek olması nedeniyle oluşturulan içeriklerin kaliteli olması gerekmektedir.

Türkiye'de teknolojinin kullanımı için 1984-2013 yılları arasında yapılan projelerin analiz edildiği yeni öğretim programlarını inceleme ve değerlendirme raporuna göre ilgili dönemde yapılan 32 projenin bilgilerine ulaşılmış ve otuz yıllık süreçte, Türk Eğitim sisteminde teknolojinin daha etkin kullanımı için azımsanmayacak miktarda yatırım yapıldığı görülmüştür. Ancak raporda belirtildiği üzere önceki yıllarda yapılan proje sonuçlarının yeterli düzeyde analiz edilemediği ve bu durumun sonucu olarak ilgili alandaki ihtiyacı karşılamak amacıyla nasıl bir proje yapılması gerektiği analiz edilmeksizin sadece teknolojiyi satın almanın yeterli olacağı düşüncesinin hâkim olduğu gözlenmiştir. (Eğitim Reformu Girişimi, 2005). Türkiye'de eğitim projeleri için yapılan yatırımların yeterince izlenmediği ve gerekli değerlendirmelerin yapılmadığı, geçmiş projelerin eksikliklerinin ve ihtiyaçlarının yeterince saptanmadığı da tespitler arasında yer almıştır. Teknolojik yatırımların içeriklerinde ve öğretim materyallerindeki yetersizliklerin devam etmesi, teknolojinin başarılı bir şekilde eğitime entegre edilememiş olduğunu göstermektedir (Topuz ve Göktaş, 2015).

EBA'da bulunan Türkçe videolarının incelendiği bir başka araştırmada, videoların Türkçe öğretimi bakımından 'etkin materyal' olma özelliği taşımadıkları belirtilmiştir. Bunun sebebi olarak videoların etkin bir öğretimi sağlaması için farklı öğretim yöntem ve tekniklerden yararlanmamış olunması ve videoların bir öğretmenin sunuş yoluyla öğretim yaklaşımını kullanarak dersleri bilgi verici bir tutumla anlatmış olması gösterilmiştir (Ateş, Çerçi ve Derman, 2015).

EBA içeriklerinin eğitsel yazılım değerlendirme ölçütlerine göre değerlendirildiği araştırmada, çoklu ortam ögelerinden yeterince yararlanılarak, zenginliğin sağladığı materyal sayılarının oldukça sınırlı olduğu, farklı öğrenme stillerine sahip öğrencilerin desteklendiği çoklu ortam ögeleriyle çeşitlendirmenin her alanda artırılması gerekli olduğu belirtilmiştir. Ayrıca, öğretim yazılımlarının tasarlanmasında, çeşitli çoklu ortam ögelerinden yararlanılabileceği gibi materyallerin üzerinde değişiklik yapabilme ve kendi branşına göre özelleştirme yapabilme olanağının sunulması için yeterli yardım ve yönlendirmenin sağlanmasının gerekli olduğu önerilmiştir. Öğrencilerin ön bilgilerinin sınandığı ve sonuçlara göre temel-orta-ileri düzey sınıflandırmalarla öğrencinin seviyesine uygun sıralanan materyallerin eksikliği vurgulanmıştır (Erensayın ve Güler, 2017). Araştırmada, öğretmenler ve öğrenciler tarafından başlıca kaynak olarak başvurulan, eğitsel bir içerik sağlama amacı olan dijital platformda yer alan videoların çoklu ortam tasarım ilkelerine uygunluğu açısından incelenerek değerlendirilmiş ve bu araştırma ile uygun içerik üretiminin önemi vurgulanmıştır. 


\section{Araştırmanın Amacı}

Öğretmen ve öğrenciler tarafından başlıca kaynak olarak başvurulan, eğitsel bir içerik sağlama amacı olan dijital platformda bulunan 3. sınıf hayat bilgisi dersindeki videoların Mayer'in Çoklu Ortam Yedi Temel Tasarım İlkesi'ne göre değerlendirilerek, çoklu ortam elemanlarının tasarım ve geliştirme aşamasında ölçütlere ne düzeyde dikkat edildiğinin ortaya konulması amaçlanmıştır.

Bu genel amaca ulaşmak için şu sorulara cevap aranmıştır:

1. Araştırma kapsamında incelenen videoların, Mayer'in Çoklu Ortam Tasarım İlkeleri'ne uygunluğu nedir?

2. İzlenen videoların (Mayer'in) değerlendirme ilkeleri arasında anlamlı korelasyonlar var midir?

3. Videoları değerlendirenlerin değerlendirme ilkelerine yönelik puanları arasında anlamlı farklar var midır?

\section{Yöntem}

\section{Araştırmanın Modeli}

$\mathrm{Bu}$ araştırmada, nitel araştırma yöntemlerinden, doküman incelemesi modeli kullanılmıştır. Doküman inceleme, araştırılması hedeflenen olgu veya olgular hakkında bilgi içeren yazılı materyallerin analizini kapsamaktadır (Yıldırım ve Şimşek, 2013). Bu araştırmada da öğretmen ve öğrenciler tarafından başlıca kaynak olarak başvurulan, eğitsel bir içerik sağlama amacı olan dijital platformda bulunan üçüncü sınıf hayat bilgisi dersindeki videolar Mayer'in Çoklu Ortam Tasarım İlkeleri'ne göre analiz edilerek çoklu ortam tasarım ölçütlerine ne düzeyde dikkat edildiğinin ortaya konulması amaçlanmıştır.

\section{Veri Kaynağı}

Araştırmanın veri kaynağını ilkokulda dijital platformlarda kullanılan videolar oluşturmaktadır. İlkokul materyal sayıları incelendiğinde en çok içeriğin 3. sınıflarda olduğu görülmüştür. Alanda yapılan araştımalar incelendiğinde ise hayat bilgisi dersine yönelik değerlendirmelerde eksiklikler saptanmıştır. Bu nedenle ilkokul sınıfları arasından içerik açısından en fazla materyale sahip olduğu göz önünde bulundurularak araştırma, ilkokul 3. sınıf ve hayat bilgisi dersi ile sınırlandırılmıştır. $\mathrm{Bu}$ sebeple araştırmanın örneklemini, dijital platform video materyallerinden ilkokul 3. sınıf hayat bilgisi filtresinde ortaya çıkan ders videoları oluşturmaktadır. Ancak bu bölümde yanlızca eğitim videoları değil, konu testleri ve yazdırılabilir eğitim materyalleri de olduğundan bunlardan sadece çoklu ortam videosu olarak nitelendirilebilecek eğitim videoları seçilerek çoklu ortam tasarım kriterlerine göre incelenmiştir. Bu bağlamda araştırmanın örneklemini, dijital platformdaki ilkokul 3. sınıf hayat bilgisi dersinde yer alan 41 video materyali oluşturmaktadır. 


\section{Veri Toplama Araçları}

Araştırmada, Ozan (2013) tarafından hazırlanan, çoklu ortam uygulamalarına ilişkin değerlendirme tablosundan faydalanılmıştır. Araştırmada, öncelikle Mayer'in (2009) çoklu ortam tasarım ilkeleri belirlenerek, Ozan'ın (2013) “Bağlantıcı Mobil Öğrenme Ortamlarında Yönlendirici Destek" başlıklı doktora tezinde oluşturup kullandığı ve kullanma izni alınan "Eğitim Amaçlı Çoklu Ortam Uygulamalarına İlişkin Değerlendirme Tablosu" başlıklı veri toplama aracı kullanılmıştır. 1'den 4'e kadar dereceleme anahtarı kullanılmıştır. 1 en düşük 4 ise en yüksek derecelemeyi oluşturmaktadır. Dereceli puanlama anahtarı kullanılarak incelenecek olan videoların yaklaşık 30 tanesi bağımsız gözlemciler arası uyum oranının belirlenmesi için araştırmacı dışında başka bir bilişim teknolojileri öğretmeni tarafından da incelenerek kodlanmıştır. Araştırmacılar arası uyuma bakılırken gözlemcilerin verdiği puanlar arasındaki ilişki korelasyon değeri hesaplanarak incelenmiştir. Gözlemciler arası uyumu belirlemek için hesaplanan korelasyon değeri .85 olarak tespit edilmiş olup gözlemcilerin içerikleri inceleme sürecinde verdikleri puanların yüksek ve pozitif yönde ilişkili olduğu görülmüştür. Bu değerlendirme tablosunda çoklu ortamlar tasarlanırken bilginin farklı kanallarda (görsel ve işitsel) işlenmesine uygun zihinsel modellerin yapılandırılması ve doğru yaklaşımların kullanılması öğrenmeyi kolaylaştırmak ve öğrenen merkezli bir yapı tasarlayabilmek adına önemlidir. Bu doğrultuda yukarıda bahsi geçen ilkeler temel alınarak geliştirilmiştir. Araştırma kapsamında biri profesör iki tanesi yüksek lisans öğrencisi olan uzamanlara Ozan (2013) tarafından geliştirilen "Eğitim Amaçlı Çoklu Ortam Uygulamlarına İlişkin Değerlendirme Tablosu” başlıklı veri toplama aracı dağıtılmıştır. Değerlendirme aracı ile ilgili uzmanlara bilgiler verildikten sonra dijital platformda yer alan hayat bilgisi dersinde belirlenen 42 videonun birbirinden bağımsız değerlendirilmesi istenmiştir. Her video için 1'den 4'e kadar dereceli puanlama anahtarı kullanılmıştır. Uzmanlardan en yüksek 4 puan ve en düşük olarak 1 puan olacak şekilde videoları değerlendirmeleri istenmiştir.

\section{Verilerin Analizi}

Veriler SPSS paket programı kullanılarak analiz edilmiştir. Verilerin analizi için öncelikli olarak SPSS programında her bir video için uzmanların toplam puanları hesaplanmıştır. Bu bağlamda videoların Mayer'in Çoklu Ortam Tasarım İlkeleri'ne uygunluğu analiz edilmiştir. İzlenen videoların değerlendirme ilkeleriyle aralarında anlamlı bir ilişki olup olmadığını kontrol etmek için Pearson korelasyon analizi kullanılmıştır. Verilerimiz normal dağılım gösterdiği için Pearson korelasyon analizi kullanılmıştır. Verilerin analizi sonucunda sayısal değerlerinin yanında eğer iki yıldız varsa (**) 0.01 düzeyinde anlamlı bir ilişki olduğu tek yıldız $\left(^{*}\right)$ varsa 0.05 düzeyinde anlamlı bir ilişki olduğu belirtilmiştir. Videoların değerlendirme ilkelerine göre videoları değerlendiren uzmanların her video için verilen puanların ortalamaları arasında anlamlı bir şekilde farklılaşıp 
farklılaşmadıklarını analiz etmek için istatiksel analiz tekniği olarak t-testi ve tek yönlü varyans analizi (ANOVA) kullanılmıştır. Varyans analizi sonucunda elde edilen $\mathrm{f}$ değerinin anlamlı bulunduğu durumlarda bu farkın hangi gruptan (düzeyden) kaynaklandığını bulmak amacıyla varyans analizi sonrası Scheffe Testi kullanılmıştır. Anlamlılık düzeyi .05 olarak kabul edilmiştir.

\section{Bulgular}

Araştırmanın bu bölümünde öğretmen ve öğrenciler tarafından başlıca kaynak olarak başvurulan, eğitsel bir içerik sağlama amacı olan dijital platformda bulunan 3. sınıf hayat bilgisi dersindeki videolar Mayer'in Çoklu Ortam Yedi Temel Tasarım İlkesi'ne göre değerlendirilerek, çoklu ortam elemanlarının tasarım ve geliştirme aşamasında ölçütlere ne düzeyde dikkat edildiği analiz edilmiş ve bulgular tablolaştırılarak sunuluştur. Kısacası, araştırma kapsamında analizler sonucu elde edilen bulgular araştırmanın soruları doğrultusunda sıra ile sunulmuştur.

\section{Araştırma Kapsamında İncelenen Videoların, Mayer'in Çoklu Ortam Tasarım İlkeleri'ne Uygunluğu}

Tablo 1. Videoların, Mayer'in Çoklu Ortam Tasarım İlkelerine Uygunluğuna İlişkin Sonuçlar

\begin{tabular}{|c|c|c|c|c|c|c|c|c|}
\hline $\begin{array}{l}\text { Video } \\
\text { No }\end{array}$ & $\begin{array}{l}\text { Çoklu } \\
\text { Ortam } \\
\text { Ilkesi }\end{array}$ & $\begin{array}{l}\text { Görsel } \\
\text { Bitişiklik } \\
\text { Ilkesi }\end{array}$ & $\begin{array}{l}\text { Biçim } \\
\text { Ilkesi }\end{array}$ & $\begin{array}{l}\text { Zamansal } \\
\text { Bitişiklik } \\
\text { Ilkesi }\end{array}$ & $\begin{array}{l}\text { Tutarlilik } \\
\text { Ilkesi }\end{array}$ & $\begin{array}{l}\text { Bireyselleştirme } \\
\text { Ilkesi }\end{array}$ & $\begin{array}{l}\text { Gereksizlik } \\
\text { Ilkesi }\end{array}$ & Toplam \\
\hline V25 & 10 & 12 & 11 & 11 & 12 & 11 & 9 & 24.00 \\
\hline V39 & 12 & 12 & 11 & 12 & 12 & 12 & 7 & 24.00 \\
\hline V14 & 10,00 & 12,00 & 11,00 & 11,00 & 12,00 & 12,00 & 7,00 & 23,67 \\
\hline V19 & 12,00 & 11,00 & 11,00 & 12,00 & 12,00 & 12,00 & 7,00 & 23,67 \\
\hline V29 & 10,00 & 12,00 & 11,00 & 11,00 & 12,00 & 12,00 & 7,00 & 23,67 \\
\hline V37 & 12,00 & 12,00 & 11,00 & 12,00 & 12,00 & 12,00 & 6,00 & 23,67 \\
\hline V8 & 12,00 & 11,00 & 9,00 & 12,00 & 11,00 & 12,00 & 8,00 & 23,67 \\
\hline V28 & 10,00 & 12,00 & 11,00 & 11,00 & 12,00 & 12,00 & 7,00 & 23,00 \\
\hline V30 & 10,00 & 12,00 & 11,00 & 11,00 & 12,00 & 12,00 & 7,00 & 23,00 \\
\hline V40 & 10,00 & 12,00 & 11,00 & 11,00 & 12,00 & 12,00 & 6,00 & 22,67 \\
\hline V20 & 10,00 & 11,00 & 11,00 & 11,00 & 12,00 & 12,00 & 7,00 & 22,00 \\
\hline V36 & 10,00 & 12,00 & 11,00 & 11,00 & 12,00 & 12,00 & 6,00 & 22,00 \\
\hline V4 & 12,00 & 9,00 & 11,00 & 12,00 & 12,00 & 12,00 & 6,00 & 21,67 \\
\hline V11 & 12,00 & 6,00 & 11,00 & 12,00 & 12,00 & 9,00 & 3,00 & 21,33 \\
\hline V13 & 10,00 & 6,00 & 11,00 & 11,00 & 12,00 & 9,00 & 4,00 & 21,33 \\
\hline V26 & 10,00 & 6,00 & 11,00 & 11,00 & 12,00 & 9,00 & 4,00 & 21,33 \\
\hline V33 & 10,00 & 6,00 & 11,00 & 11,00 & 12,00 & 9,00 & 4,00 & 21,33 \\
\hline V31 & 10,00 & 6,00 & 11,00 & 11,00 & 12,00 & 9,00 & 4,00 & 21,00 \\
\hline V41 & 10,00 & 6,00 & 11,00 & 11,00 & 12,00 & 9,00 & 4,00 & 21,00 \\
\hline V5 & 12,00 & 9,00 & 11,00 & 12,00 & 12,00 & 12,00 & 6,00 & 21,00 \\
\hline V15 & 10,00 & 9,00 & 9,00 & 11,00 & 12,00 & 10,00 & 5,00 & 20,67 \\
\hline V2 & 10,00 & 4,00 & 11,00 & 11,00 & 10,00 & 10,00 & 5,00 & 20,67 \\
\hline V21 & 10,00 & 9,00 & 11,00 & 11,00 & 12,00 & 9,00 & 5,00 & 20,67 \\
\hline V24 & 10,00 & 9,00 & 9,00 & 11,00 & 11,00 & 10,00 & 5,00 & 20,67 \\
\hline V3 & 12,00 & 5,00 & 9,00 & 11,00 & 10,00 & 11,00 & 6,00 & 20,67 \\
\hline V22 & 10,00 & 3,00 & 11,00 & 11,00 & 12,00 & 9,00 & 4,00 & 20,33 \\
\hline V1 & 11,00 & 4,00 & 10,00 & 10,00 & 11,00 & 10,00 & 5,00 & 20,00 \\
\hline V38 & 12,00 & 3,00 & 11,00 & 12,00 & 12,00 & 9,00 & 4,00 & 20,00 \\
\hline V9 & 12,00 & 3,00 & 11,00 & 12,00 & 12,00 & 9,00 & 4,00 & 20,00 \\
\hline
\end{tabular}




\begin{tabular}{lllllllll}
\hline V12 & 10,00 & 3,00 & 11,00 & 11,00 & 12,00 & 9,00 & 4,00 & 19,67 \\
\hline V27 & 10,00 & 3,00 & 11,00 & 11,00 & 12,00 & 9,00 & 4,00 & 19,67 \\
\hline V32 & 10,00 & 3,00 & 11,00 & 11,00 & 12,00 & 9,00 & 4,00 & 19,67 \\
\hline V34 & 10,00 & 3,00 & 11,00 & 11,00 & 12,00 & 9,00 & 4,00 & 19,67 \\
\hline V6 & 11,00 & 4,00 & 11,00 & 11,00 & 12,00 & 10,00 & 5,00 & 19,67 \\
\hline V10 & 10,00 & 3,00 & 11,00 & 11,00 & 12,00 & 9,00 & 4,00 & 19,00 \\
\hline V16 & 10,00 & 3,00 & 11,00 & 11,00 & 12,00 & 9,00 & 4,00 & 19,00 \\
\hline V17 & 10,00 & 3,00 & 11,00 & 11,00 & 12,00 & 9,00 & 4,00 & 19,00 \\
\hline V35 & 10,00 & 3,00 & 11,00 & 11,00 & 12,00 & 9,00 & 4,00 & 19,00 \\
\hline V18 & 10,00 & 9,00 & 9,00 & 11,00 & 11,00 & 10,00 & 5,00 & 18,67 \\
\hline V7 & 11,00 & 7,00 & 11,00 & 11,00 & 12,00 & 10,00 & 4,00 & 18,67 \\
\hline
\end{tabular}

Tablo 1 incelendiğinde, videoların Mayer'in Çoklu Ortam Tasarım İlkeleri'ne uygunluğu dikkate alındığında en yüksek toplam puanın 'Dikkatli Olalım' başlıklı Video 25'e ait olduğu sonucuna ulaşılmıştır. Toplam en düşük puanın ise 'Demokratik Çözümler' başlıklı Video 7'ye ait olduğu sonucuna ulaşılmıştır. Video 25'in görsel bitişiklik ve tutarlılık ilkesinden uzmanlar tarafından tam puan aldığı, gereksizlik ilkesinden ise en düşük puanı aldığı sonucuna ulaşılmıştır. Video 7'de ise tutarlılık ilkesinden uzmanlar tarafından tam puan aldığı, gereksizlik ilkesinden ise en düşük puanı aldığı sonucuna ulaşılmıştır. İlkelere genel olarak bakıldığında en yüksek puanı (12 puan) alan ilke tutarlılık ilkesi olmuştur.

Çoklu ortam ilkesi uzmanlar tarafından 10 videoda tam puan almıştır, 3 tane videodan 11 puan, 27 tane videodan ise 10 puan almıştır. Bu ilke diğer ilkelere kıyasla uzmanlar tarafından tam puana yakın değerler almıştır. Bu bulgulara göre ise videoların tanımlamalarda ya da kavramsal ilişkileri gösterirken tablo, grafik, animasyon gibi görsel içerikleri bolca kullanması bakımından çoklu ortam ilkesini yerine getirdiği sonucuna ulaşılabilir. Görsel bitişiklik ilkesine bakıldığında ise uzmanlar tarafından 9 tane 12 puan aldığı, 3 tane 11 puan, 6 tane 9 puan, 1 tane 7 puan, 1 tane 5 puan, 3 tane 4 puan, 11 tane 3 puan aldığı görülmektedir. Bu bulgulara göre videolarda yazı ve görsellerin birlikte kullanıldığı, bu bakımdan görsel bitişiklik ilkesi gereğince vurgulanmak istenilen yerde görsellerin kelimelerle desteklenmesi gerekliliği özelliğine uymamaktadır. Görsellere ait açıklamalar değerlendirilen videoların çoğunluğunda farklı ekranlarda veya pencerelerde verilmiştir. Biçim ilkesine bakıldığında ise videoların uzmanlar tarafından tam puanın almadığı, 34 tane 11 puan, 1 tane 10 puan, 5 tane 9 puan aldığı bulgusuna ulaşılmıştır. Tam puanın olmamasında videoların hepsinde yazılı metinler yerine sesli anlatımların kullanılması gerekliliğine uyulmadığı bulgusuna ulaşılabilir. Videoların çoğundan 11 puan alınması, genel anlamda videolarda görsellerin büyük bir kısmının sesli anlatımlar ile açıklandığı sonucunu vermektedir.

Zamansal bitişiklik ilkesine bakıldığında ise uzmanlar tarafından videolardan 9 tane 12 puan, 30 tane 12 puan, 1 tane 10 puan alındığı görülmektedir. Bu bulguya göre videoların zamansal bitişiklik ilkesi gereğince görsellerle sözel anlatımın eş zamanlı verildiği sonucuna ulaşılabilir. Gereksizlik ilkesine bakıldığında ise uzmanlar tarafından tam puan almamış ve düşük puanlarla 
değerlendirilmiştir. Bu bulgulara göre videolarda öğrenene istediği zaman anlatımı yazılı olarak görme seçeneği sunulmamıştır. Videolarda uzmanlar tarafından en yüksek puanı alan ilke ise tutarlılık ilkesidir. Tutarlılık ilkesi videoların çoğunda tam puan almıştır. Bu bulguya göre videolarda gereksiz bilgi verilmemiş ve parçalar arasında bağlantı kurulup konudan sapma yaşanmamıştır.

$\mathrm{Bu}$ doğrultuda videolarda ilginç ama konu ile alakası olmayan detaylara yer verilmemiştir. Ayrıca videolarda açık, sade ve net ifadeler kullanılmıştır. Bireyselleştirme ilkesi ise uzmanlar tarafından toplamda 9 puan ve 12 tam puan arasında değerlendirilmiştir. Videoların çoğunun 9 puan alması ise öğrenenlerin bireysel farklılıklarının tam anlamıla göz önünde bulundurulmadığı ancak genel anlamda kontrolün öğrenende olduğu sonucuna ulaşılmaktadır.

\section{Videoların Değerlendirme İlkeleri Arasındaki Korelasyon Sonuçları}

İzlenen videoların değerlendirme ilkeleri arasında anlamlı ilişki olup olmadığı kontrol edilmiştir. Bu amaçla Pearson korelasyon analizi yapılmış ve bulgular Tablo 2'de verilmiştir.

Tablo 2. Videoların Değerlendirme İlkeleri Arasındaki Korelasyon Sonuçları

\begin{tabular}{|c|c|c|c|c|c|c|c|c|}
\hline & & $\begin{array}{l}\text { Çoklu } \\
\text { ortam } \\
\end{array}$ & Görsel & Biçim & Zaman & Tutarlık & Bireysellik & Gereksiz \\
\hline \multirow[t]{3}{*}{$\begin{array}{l}\text { Çoklu } \\
\text { ortam }\end{array}$} & $\begin{array}{l}\text { Pearson } \\
\text { Correlation }\end{array}$ & 1 & 102 &,- 068 &, $785^{* *}$ &,- 107 & , 328* & 193 \\
\hline & Sig. (2-tailed) & &, 527 & 672 & ,000 & ,505 & ,036 & ,228 \\
\hline & $\mathrm{N}$ & 41 & 41 & 41 & 41 & 41 & 41 & 41 \\
\hline \multirow[t]{3}{*}{ Görsel } & $\begin{array}{l}\text { Pearson } \\
\text { Correlation }\end{array}$ & 102 & 1 &,- 069 & ,225 & 111 &, $848^{* *}$ & $819^{* *}$ \\
\hline & Sig. (2-tailed) &, 527 & & 670 & 157 & ,491 & ,000 & ,000 \\
\hline & $\mathrm{N}$ & 41 & 41 & 41 & 41 & 41 & 41 & 41 \\
\hline \multirow[t]{3}{*}{ Biçim } & $\begin{array}{l}\text { Pearson } \\
\text { Correlation }\end{array}$ & -,068 &,- 069 & 1 & 116 & $669^{* *}$ & ,014 &,- 050 \\
\hline & Sig. (2-tailed) & 672 & 670 & & ,471 & ,000 & ,933 & 755 \\
\hline & $\mathrm{N}$ & 41 & 41 & 41 & 41 & 41 & 41 & 41 \\
\hline \multirow[t]{3}{*}{ Zaman } & $\begin{array}{l}\text { Pearson } \\
\text { Correlation }\end{array}$ &, $785^{* *}$ & ,225 & ,116 & 1 & , 182 & 297 & 182 \\
\hline & Sig. (2-tailed) & ,000 & 157 & ,471 & & ,255 & ,060 & 254 \\
\hline & $\mathrm{N}$ & 41 & 41 & 41 & 41 & 41 & 41 & 41 \\
\hline \multirow[t]{3}{*}{ Tutarlık } & $\begin{array}{l}\text { Pearson } \\
\text { Correlation }\end{array}$ &,- 107 & 111 & $669^{* *}$ & 182 & 1 &,- 009 &,- 056 \\
\hline & Sig. (2-tailed) &, 505 & ,491 & ,000 & ,255 & & ,958 & ,730 \\
\hline & $\mathrm{N}$ & 41 & 41 & 41 & 41 & 41 & 41 & 41 \\
\hline \multirow[t]{3}{*}{ Bireysellik } & $\begin{array}{l}\text { Pearson } \\
\text { Correlation }\end{array}$ & ,328* & $848^{* *}$ & ,014 & 297 &,- 009 & 1 &, $888^{* *}$ \\
\hline & Sig. (2-tailed) & ,036 & ,000 & ,933 & ,060 & ,958 & & ,000 \\
\hline & $\mathrm{N}$ & 41 & 41 & 41 & 41 & 41 & 41 & 41 \\
\hline \multirow[t]{3}{*}{ Gereksiz } & $\begin{array}{l}\text { Pearson } \\
\text { Correlation }\end{array}$ & 193 & $819^{* *}$ &,- 050 & 182 & -,056 &, $888^{* *}$ & 1 \\
\hline & Sig. (2-tailed) & ,228 & ,000 & ,755 & ,254 & 730 & ,000 & \\
\hline & $\mathrm{N}$ & 41 & 41 & 41 & 41 & 41 & 41 & 41 \\
\hline
\end{tabular}


Tablo 2 incelendiğinde yapılan Pearson korelasyon analizinde biçim ve tutarlık ilkesi $(r=, 669$, $\mathrm{p}<, 001)$, zamansal bitişiklik ve çoklu ortam ilkesi $(\mathrm{r}=, 785, \mathrm{p}<, 001)$, görsel bitişiklik ve gereksizlik ilkesi $(\mathrm{r}=, 819$, $\mathrm{p}<, 001)$, görsel bitişiklik ve bireyselleştirme ilkesi $(\mathrm{r}=, 848, \mathrm{p}<, 001)$, bireyselleştirme ve çoklu ortam ilkesi $(r=, 328, p<, 05)$ arasında anlamlı ve olumlu bir ilişki olduğu bulunmuştur. En yüksek anlamlı ilişki bireyselleştirme ve gereksizlik ilkesi $(r=, 888, p<, 001)$ arasında ortaya çıkmıştır. Çoklu ortam ve görsellik arasında anlamlı bir ilişkinin bulunmadığı sonucuna ulaşılabilir. Pearson korelasyon değerine bakıldığında da değerin 0'a yakın olması aralarında nötr bir ilişki olduğunu göstermektedir. Çoklu ortam ve biçim arasında anlamlı bir ilişkinin bulunmadığı sonucuna ulaşılabilir. Pearson korelasyon sonucuna bakıldığında da değerin 0'a yakın olması aralarında nötr bir ilişki olduğunu göstermektedir. Çoklu ortam ve zaman arasında anlamlı bir farklılığın olduğu görülmektedir. Pearson korelasyon değerinin 0,785 bulunması olumlu yönde korelasyonel bir ilişkinin bulunduğunu göstermektedir. Çoklu ortam ve tutarlılık arasında anlamlı bir farklılığın olmadığı sonucuna ulaşılmıştır. Pearson değeri de 0'a yakın olması bakımından aralarında nötr bir ilişki olduğunu göstermektedir. Çoklu ortam ve bireysellik arasında anlamlı bir farklılık olduğu fakat Pearson korelasyon sonucuna göre bu anlamlılığın pozitif yönde ve çok güçlü olmadığı görülmektedir. Çoklu ortam ve gereksizlik ilkeleri arasında ise anlamlı bir farklılığın olmadığı ve Pearson korelasyon sonucuna göre aralarındaki ilişkinin nötre yakın olduğu sonucuna ulaşılmıştır. Görsel ve biçim, görsel ve zaman, görsel ve tutarlılık ilkeleri arasında anlamlı bir farklılığın olmadığı ve bu ilişkinin Pearson'a göre nötre yakın olduğu sonucuna ulaşılmıştır. Görsel ve bireysellik, görsel ve gereksizlik ilkeleri arasında anlamlı bir farklılığın olduğu ve Pearson korelasyon değerine göre bu farklılığın pozitif yönde olduğu sonucuna ulaşılabilir. Biçim ve zaman, biçim ve bireysellik, biçim ve gereksizlik ilkeleri arasında anlamlı bir farklılığın olmadığı aralarındaki ilişkinin nötre yakın olduğu sonucuna ulaşılmıştır. Biçim ve tutarlılık ilkeleri arasında ise anlamlı bir farklılığın olduğu ve bu farklılığın pozitif yönde olduğu sonucuna ulaşılmıştır. Zaman ve tutarlılık, zaman ve bireysellik, zaman ve gereksizlik arasında anlamlı bir farklılı̆̆ın olmadığı ve aralarındaki ilişkinin nötre yakın olduğu sonucuna ulaşılmıştır. Tutarlılık ve bireysellik, tutarlılık ve gereksizlik, bireysellik ve gereksizlik ilkeleri arasında da anlamlı bir farklılı̆̆ın olmadığı sonucuna ulaşılmıştır.

\section{Uzmanların Dijital Platformdaki Videoların Mayer'in Çoklu Ortam Tasarım İlkelerine Göre}

\section{Değerlendirmelerine İlişkin Bulgular}

Araştırmada değerlendirilmeye alınan videoların Mayer'in Çoklu Ortam Yedi Temel Tasarım İlkesi'ne göre değerlendiren uzmanların her video için verilen değerlendirme puanlarının anlamlı bir farklılık gösterip göstermediğine ilişkin betimsel istatistikler Tablo 3 ve tekrarlı ölçümler için ANOVA sonuçları Tablo 4 'te verilmiştir. 
Tablo 3. Uzmanlarının Değerlendirme Puanlarının Betimsel İstatistikleri

\begin{tabular}{lllll}
\hline & Uzmanlar & $\boldsymbol{N}$ & $\boldsymbol{X}$ & $\boldsymbol{S} \boldsymbol{d}$ \\
\hline 1. & Uzman & 41 & 22,48 & 2,08 \\
2. & Uzman & 41 & 22,09 & 1,86 \\
3. & Uzman & 41 & 18,53 & 2,44 \\
\hline
\end{tabular}

Tablo 4. Faktörlere İlişkin Puanların Uzmanlara Göre ANOVA Sonuçları

\begin{tabular}{lllllll}
\hline Varyansın Kaynăğ & KT & $s d$ & KO & $f$ & P & $\begin{array}{c}\text { Anlamli } \\
\text { Fark }\end{array}$ \\
\hline Uzmanlar arası & 342,130 & 40 & 8,553 & & \\
Ölçüm & 388.748 & 2 & 194.374 & 74.07 & .000 & $1>3 ; 2>3$ \\
Hata & 209.919 & 80 & 2.624 & & \\
Toplam & 940.797 & 122 & & & \\
\hline 1: Birinci uzman değerlendirmesi, 2: İkinci uzman değerlendirmesi, 3: Üçüncü uzman değerlendirmesi
\end{tabular}

Tablo 3 incelendiğinde dijital platformda yer alan hayat bilgisi dersi videolarını, Mayer'in Çoklu Ortam Tasarım İlkeleri'ne göre değerlendiren uzmanların, her video için verilen değerlendirme puanları arasında anlamlı bir farklılık olduğu (f $(2.80)=74.07, \mathrm{p}<.01)$ bulunmuştur. İkinci uzmanın videolara verdiği ortalama puanı $(X=22.09)$ ve birinci uzmanın videolara verdiği ortalama puanı $(X=22,48)$, üçüncü uzmanın videolara verdiği ortalama puana $(X=18.53)$ göre daha yüksektir. Öte yandan birinci uzman ve ikinci uzman puanları arasındaki fark anlamlı bulunmamıştır. Bu bulgu, dijital platformda hayat bilgisi dersi videolarını, Mayer'in Çoklu Ortam Tasarım İlkeleri'ne göre değerlendiren uzmanların, her video için verilen değerlendirme puanları arasında birinci ve ikinci uzman puanları arasında bir fark olmazken üçüncü uzmanın vermiş olduğu puanlarla diğer uzmanların puanları arasında anlamlı bir farklılık olduğunu göstermektedir. Bir diğer ifadeyle videoları inceleyen uzmanlar ilkeleri değerlendirirken verdikleri puanlar yönünden bir ve ikinci uzman hariç farklı değerlendirme sonuçlarına ulaşmış şeklinde yorumlanabilir.

\section{Sonuç ve Tartışma}

Araştırmanın sonucunda Mayer'in Çoklu Ortam Tasarım İlkeleri'ne uygunluğuna göre değerlendirilen videoların çoklu ortam ilkesine uygun görüldüğü bu bağlamda videolarda çoklu ortam ögelerinin (metin, ses, görsel, video vb.) birbirini tamamlayan, karmaşadan uzak, sade ve konunun sunumunu güçlendirecek şekilde organize edildiği görülmüştür. Kullanımın kolay olması için kullanıcıların, sunulan içerik ve gezinme üzerinde söz sahibi olabilmeleri, sunulan içeriğe ilişkin kontrollerden en önemlisinin, videoyu tekrar etme, başa alma, istedikleri anda durdurma şanslarının olması gerekmektedir (Alessi ve Trollip, 2001). Bu bağlamda videolarda, kontrolün öğrenene bırakılması, tekrar dinleme seçeneğinin sunulması gibi özellikleri kapsayan bireyselleştirme ilkesinin dikkate alındığı sonucuna ulaşılmıştır.

Videoların genelinde gereksizlik ilkesine dikkat edilmediği, öğrenenlere görsellerle ve sesli olarak aktarılan anlatımı istek hâlinde yazılı olarak görme seçeneğinin sunulmadığı sonucuna 
ulaşılmıştır. Okuyarak daha iyi anlayacağını düşünen veya işitme yetersizliği olan öğrenenler göz ardı edilmiştir. Videoların büyük bir çoğunluğunda görsel ögeler, sesli anlatım ve metinlerle birlikte sunulmuştur. $\mathrm{Bu}$ durumda kullanıcı bilişsel olarak yüklenmekte ve öğrenmede zorluklar yaşanmaktadır. Bu araştırma sonucuna paralel olarak Kılıç-Çakmak (2007) çoklu ortamlara dayalı öğretimde, paralel tasarım ve görev zorluğunun, başarı ve bilişsel yüklemeye etkisini incelediği araştırmada öğrencilerin çalıştıkları ortam dikkate alınmadığında, öğrencilerin bilişsel yük puanlarının, verilen görevin zorluk düzeyine göre anlamlı farklılık gösterdiği sonucuna ulaşılmıştır. $\mathrm{Bu}$ bulgulardan hareketle, çoklu ortamların tasarlanması sürecinde, öğrencilerin bilişsel olarak yüklenmelerini engellemek ve başarıyı artırmak için biçim, gereksizlik, tutarlılık, bitişiklik ve bölünmüş dikkat ilkelerinin göz önünde bulundurulmasının faydalı olacağını belirtmektedir. Görsel ve zamansal bitişiklik ilkeleri doğrultusunda da konular küçük parçalara bölünerek görsel ve sözel anlatım aynı anda verilmiştir.

Araştırmanın bulgularına bakıldığında, izlenen videoların değerlendirme ilkeleri arasında anlamlı bir farklılık olduğu sonucuna ulaşılmıştır. Bu ilkeler; biçim ve tutarlılık ilkesi, zamansal bitişiklik ve çoklu ortam ilkesi, görsel bitişiklik ve gereksizlik ilkesi, görsel bitişiklik ve bireyselleştirme ilkesi, bireyselleştirme ve çoklu ortam ilkesi, bireyselleştirme ve gereksizlik ilkesidir. Bireyselleştirme ve gereksizlik ilkesi arasında en yüksek anlamlı ilişki bulunmuştur. Ayrıca videoyu değerlendiren uzmanlar arasında birinci ve ikinci uzman hariç farklı değerlendirme sonuçlarına ulaşılması dijital platformların değerlendirilmesinde birden fazla uzmandan görüş ve destek alınması gerektiğini göstermektedir. Bu bağlamda araştırma uygun içerik üretimi konusunda yazılımcılara da yardımcı bir kaynak olacaktır.

İlgili alan yazın incelendiğinde öğrenenin, birden çok duyuyu hedef alan uyaranlar içeren çoklu öğrenme ortamlarında, daha etkili ve kalıcı öğrenmeler elde ettiği yapılan araştırmalar sonucunda da ortaya konmuştur (Baek ve Layne, 1988; Mene ve Mene, 1972; Raupers, 2000; Sezgin, 2002; Shepherdson, 2001; Tsoua, Wang ve Tzeng, 2004). Yapılan araştırmalarda öğrenme öğretme süreçlerinin etkili olabilmesi için çoklu ortam bileşenlerinin gelişigüzel düzenlenmemesi gerektiği, eğitim ortamları tasarlanırken ses ve görsel ögeler için uygun öğretim tasarım ilkeleri ve bu ortamların geliştirilmesine yönelik araştırmalar ve çoklu ortam ara yüz tasarımına ilişkin ilkelerinin göz önünde bulundurulması gerektiği görülmektedir (Rogers, 2001).

$\mathrm{Bu}$ araştırmadan elde edilen bulgular ve sonuçlar eğitsel içerik sağlama amacı olan dijital platformun çoklu ortam tasarım ilkelerine uygunluğunu değerlendirmeye yöneliktir. Özellikle çoklu ortam tasarımları ve eğitim platformları ile ilgili yapılan araştırmalar değerlendirildiğinde, bu eğitim platformlarının içerik yapısının hem öğrencilere teknolojik bilgi üretiminin hazırlanması hem de bu bilgilerin etkin biçimde öğrenim sürecinde kullanılması açısından önemli olduğu görülmektedir. 
Oluşturulacak içeriklerin de öğrencilerin okuma, dinleme, izleme ve çoklu ortamlardan faydalanarak anlama düzeylerine olumlu yönde katkı sağlayacak nitelikte olması gerekmektedir. Kelly (2008), eğitsel yazılımların değerlendirilmesinin öğrenme sürecinde yazılımlarının etkilerinin görülebilmesi için bir fırsat vereceğini düşünmektedir. Bu sebeple diğer eğitimsel platformların çoklu tasarım ilkelerine göre incelenmesinin önemli olacağı düşünülmektedir. $\mathrm{Bu}$ sebeple araştırma dijital platformların değerlendirilmesiyle ilgili literatürdeki boşluğa katkı sağlayacaktır. Ayrıca eğitsel bağlamda içerik üretecek olan yazılımcılara da hangi bağlamlarda dikkat edilmesi gerektiği konusunda katkı sağlayabilir.

\section{Kaynaklar}

Akkoyunlu, B., \& Yılmaz, M. (2005). Türetimci çoklu ortam öğrenme kuramı. Hacettepe Üniversitesi Eğitim Fakültesi Dergisi, 28(28), 9-18.

Alessi, S. M., \& Trollip, S. R. (2001). Multimedia for learning metods and development (3rd Ed.). Massachusetts, USA: Allyn and Bacon.

Ateş, M., Çerçi, A., \& Derman, S. (2015). Eğitim bilişim ağında yer alan Türkçe dersi videoları üzerine bir inceleme. Sakarya University Journal of Education, 5(3), 105-125.

Baturay, H. M., \& Türel, K. Y. (2013). Çeorimiçi uzaktan eğitimcilerin eğitimi: e öğrenmenin yükselişi ile beliren ihtiyaç. G. Eby, T. G. Yamamoto, \& U. Demiray (Ed.). Türkiye'de e-öğrenme: Gelişmeler ve uygulamalar III içinde (s.1). İstanbul: Kriter.

Baek, Y., \& Layne, B. (1988). Color, garphics and animation in a computer assisted learning tutorial lesson. Journal of Computer Based Instruction, 15, 131-135.

Eğitim Reformu Girişimi. (2005). Yeni Öğretim Programlarını İnceleme ve Değerlendirme Raporu. İstanbul: Sabancı Üniversitesi Eğitim Reformu Girişimi.

Erensayın, E., \& Güler, Ç. (2017). EBA platformundaki ders materyallerinin eğitsel yazılım değerlendirme ölçütlerine göre değerlendirilmesi. Ahi Evran Üniversitesi Kırşehir Eğitim Fakültesi Dergisi, 18(1), 657-678.

Kelly, G. (2008). A collaborative process for evaluating new learning technologies. Campus Wide Information Systems, 25(2), 105-113.

Kılıç-Çakmak, E. (2007). Arayüz tasarımında yeni bir yaklaşım paralel öğretim tasarımı. Gazi Üniversitesi Gazi Eğitim Fakültesi Dergisi, 27, 1-22.

Mayer, R. E. (2009). Multimedia learning. UK: Cambridge.

MEB. (2018). İlköğretim 3. Sınıf Hayat Bilgisi Öğretim Programı, http://mufredat.meb.gov.tr/ProgramDetay.aspx?PID=326 sayfasından erişilmiştir. 
Mene, J. M., \& Mene, J. W. (1972). The relative efficiency of bimodal presentation as an aid to learning. Audio Visual Communication Review, 20, 170-180.

Olkun, S., \& Toluk-Uçar, Z. (2009). İlköğretimde etkinlik temelli matematik öğretimi. (6. Basım) Ankara: Eğiten Kitap.

Ott, J. (2000). The milennium. Information System Security, 8(4), 3-5.

Ozan, Ö. (2013). Eğitim amaçlı çoklu ortam uygulamalarına ilişkin bir değerlendirme aracı. Eskişehir Osmangazi Üniversitesi Ĕ̆itim Bilimleri Dergisi, 3(2), 56-64.

Özerbaş, M. A. (2007). Yapılandırmacı öğrenme ortamının öğrencilerin akademik başarılarına ve kalıcılı̆̆ına etkisi. Türk Ĕ̆gitim Bilimleri Dergisi, 4(5), 609-635.

Rogers, P. L. (2001). Designing instruction for technology enhanced learning. London: IRM

Raupers, P. M. (2000). Effects of accommodating learning- style preferences on long-term retention of technology training content. National Forum of Special Education Journal, 19(2000), 444-452.

Sezgin, M. E. (2002). Ikili kodlama kuramına dayalı olarak hazırlanan multimedia ders yazılımının fen bilgisi öğretimindeki akademik başarıya, öğrenme düzeyine ve kalıcılı̆̆a etkisi. (Yüksek lisans tezi). https://tez.yok.gov.tr sayfasından erişilmiştir.

Shepherdson, E. (2001). Teaching concepts utilizing active learning computer environments. http://moment.mit.edu/thesisemma/pdf\%20files/thesis.htm sayfasından erişilmiştir.

TDK. (2017). Türk Dil Kurumu. http://tdk.gov.tr/ sayfasından erişilmiştir.

Topuz, A., \& Göktaş, Y. (2015). Türk eğitim sisteminde teknolojinin etkin kullanımı için yapılan projeler: 1984-2013 dönemi. Bilişim Teknolojileri Dergisi, 8(2), 102-139.

Tsoua, W., Wang, W., \& Tzeng, Y. (2004). Applying a multimedia storytelling website in foreign language learning. Computers $\mathcal{E}$ Education, 39(4), 415-428.

Yıldırım, A., \& Şimşek, H. (2013). Sosyal bilimlerde nitel araştırma yöntemleri. Ankara: Seçkin.

\section{Extended Summary}

By evaluating the videos in the third-grade Life Studies course on the Digital platform, which is used as a primary resource by teachers and students and aims to provide educational content, according to Mayer's seven basic design principles, the level of attention to the criteria in the design and development phase of the multimedia elements is aimed to be revealed. When the related literature is examined, it has been revealed that the learner achieves more effective and permanent learning in multiple learning environments containing stimuli targeting more than one sense (Baek \& Layne, 1988; Mene \& Mene, 1972; Raupers, 2000; Sezgin, 2002; Shepherdson, 2001; Tsou, Wang, \& Tzeng, 2004). Focusing on the impact on students motivations, Neo and Yap also noted that learning environments created with multimedia content by Mayer and Nielsen have a positive impact on 
motivation. In the studies conducted, it is seen that multimedia components should not be arranged arbitrarily in order for learning and teaching processes to be effective, teaching design principles suitable for audio and visual elements, researches for the development of these environments and principles of multimedia interface design should be taken into consideration while designing educational environments (Rogers, 2001).

In another study examining Turkish videos in EBA, it was stated that the videos do not have the feature of being an "effective material" in terms of Turkish teaching. The reason for this is that the videos have not benefited from different teaching methods and techniques in order to provide effective teaching, and the videos have shown that a teacher lectures in an informative manner using the teaching approach by presentation (Ateş, Çerçi, \& Derman, 2015).

Document analysis, one of the qualitative research methods, was used in this study. Document review includes the analysis of written materials containing information about the phenomenon or cases that are aimed to be investigated (Yıldırım \& Şimşek, 2013). In this study, analyzing the videos in the third-grade life sciences course on the digital platform, which is used as a primary source by teachers and students and aims to provide educational content, according to the principles of multimedia design by Mayer, and revealing the level of attention to multimedia design criteria are intended.

In the study, the evaluation table for multimedia applications prepared by Ozan (2013) was used. As part of the study, the data collection tool entitled "Evaluation table on multimedia applications for educational purposes" developed by Ozan (2013) was distributed to experts. After information was given to the experts about the evaluation tool, 42 videos identified in the Life Studies course on the digital platform were asked to be evaluated independently of each other. A four-level rubric was used for each video; experts were asked to rate the videos with the highest score of 4 and the lowest score of 1 . The data were analyzed using the SPSS package program.

In the study, the videos in the Third Grade Life Sciences course on the Digital platform, which is used as the main source by teachers and students and which aims to provide educational content, are evaluated according to Mayer's Multimedia seven basic design principles, and multimedia design elements and criteria in video development are intended to show how much attention is paid to Mayer's design principles. In short, the findings obtained as a result of the analysis within the scope of the study concluded that the highest total score was 25 for Video 'Let's Be Careful' , considering the compliance of the videos with Mayer's Multimedia Design principles in line with the questions of the study. It was concluded that the lowest score in total belongs to Video 7 titled 'Democratic Solutions'. Also, it was infered that Video 25, received a full score from the judges on the principle of visual adjacency and consistency, and the lowest score from the principle of non-necessity. The Video 7, 
received a full score from the referees on the principle of consistency, the lowest score from the principle of non-necessity. It was checked whether there was a significant relationship between the evaluation principles of the watched videos. For this purpose, Pearson correlation analysis was performed and it was found that there is a significant and positive relationship between the form the principle of consistency $(\mathrm{r}=, 669, \mathrm{p}<, 001)$, temporal types, and multi-media policy $(\mathrm{R}=, 785, \mathrm{p}<, 001)$, visual adjacency and exemption policy $(\mathrm{R}=, 819, \mathrm{p}<, 001)$, visual adjacency and the principle of individualization $(r=, 848 \mathrm{p}<, 001)$, individualization and multi-media policy $(\mathrm{R}=, 328, \mathrm{p}<, 05)$ it was found that there is a significant and positive relationship between. The highest significant relationship between individualization and the principle of non-necessity $(\mathrm{r}=, 888, \mathrm{p}<, 001)$ has emerged. For each of the life studies course videos of Mayer's seven principles, the scores of the experts regarding whether the evaluation made according to the descriptive statistical results showed a significant difference were evaluated according to the basic design principles. As a result of the evaluation of the life science lesson videos on the digital platform by the experts who evaluated each video according to Mayer's Multimedia Design principles, it was found that there was a significant difference between the scores given for $F(2.80)=74.07, p<.01$ The second expert's average score for videos $(X=22.09)$ and the first expert's average score for videos $(X=22.48)$ are higher than the third expert's average score for videos $(x=18.53)$. On the other hand, the difference between the first expert and the second expert scores was not significant. This finding shows that while evaluating the scores given for each video according to Mayer's Multimedia Design principles in accordance with the expert evaluation of the experts in the life science lesson videos on the digital platform, there is no difference in scores between the first and second experts, and there is a significant difference between the scores of the third expert and the scores of the other experts.

The findings and results obtained from this research are intended to evaluate the compliance of the digital platform, which aims to provide educational content, with the principles of multimedia design. Especially when the studies on multimedia designs and educational platforms are evaluated, it is seen that the content structure of these educational platforms is important both in terms of preparing technological knowledge production for students and using this information effectively in the learning process. The content to be created must be of a quality that will contribute positively to the students' reading, listening, watching and comprehension levels by using multiple media. For this reason, it will be important to examine other educational platforms according to multiple design principles. The study will contribute to the gap in the literature regarding the evaluation of digital platforms. It can also contribute to the software developers who will produce content in educational context to which attention should be paid attention. 


\section{Araştırmacıların Katkı Oranı Beyanı}

Bu araştırmaya birinci yazar \%50 oranında, ikinci ve üçüncü yazar \%25 oranında katkı sağlamıştır.

\section{Destek ve Teşekkür Beyanı}

$\mathrm{Bu}$ araştırmada herhangi bir kurum, kuruluş ya da kişiden destek alınmamıştır.

\section{Çatışma Beyanı}

Araştırmacının araştırma ile ilgili diğer kişi ve kurumlarla herhangi bir kişisel ve finansal çıkar çatışması yoktur.

\section{Etik Kurul Beyanı}

$\mathrm{Bu}$ araştırma doküman incelemesi yapılarak yürütüldügünden etik kurul kararı gerektirmemektedir. 